\title{
TEMPO E DIREITO: TRADIÇÃO, PRESENTE E FUTURO DA FACULDADE DE DIREITO DA UFPR*
}

\author{
TIME AND LAW: TRADITION, PRESENT AND FUTURE \\ OF UFPR LAW SCHOOL
}

por Ricardo Marcelo Fonseca**

Magnífica Reitora em exercício da Universidade Federal do Paraná, Prof. ${ }^{a}$ Dr. ${ }^{\text {a }}$ Marcia Helena Mendonça,

Excelentíssimas autoridades acadêmicas e institucionais presentes, Pró-Reitoras e Pró-Reitores, Diretores de Setor, Magistrados, Advogados, que eu cumprimento na pessoa da Pró-Reitora de Extensão e Cultura da UFPR, professora Sandra Guimarães,

Ilustríssimo coordenador do programa de pós-graduação em direito da UFPR, Prof. Dr. Erouths Cortiano Jr.,

Ilustríssimo presidente do Centro Acadêmico Hugo Simas, Daniel Hachem,

Caríssimos professores e colegas aqui presentes, que eu cumprimento na pessoa do prof. Dr. José Antonio Peres Gediel,

Caríssimos estudantes, da graduação e da pós-graduação, desta Casa,

Caros familiares, queridos amigos aqui presentes,

* Discurso de posse como Diretor da Faculdade de Direito da UFPR, em cerimônia ocorrida no dia 11 de julho de 2008, no Salão Nobre da Faculdade.

** Professor da Faculdade de Direito da UFPR dos Programas de Graduação e Pós-Graduação. Pesquisador do CNPq.
Senhoras e senhores.

Vivemos, hoje, a inflexão do tempo. O mundo está mudando, o direito está mudando, a ciência está mudando. E o curso de direito da UFPR está mudando.

Tempo e direito têm uma relação crucial. Não é possível conhecer o direito senão a partir de uma perspectiva temporal. O direito só se revela realmente e só desabrocha para o estudioso quando apreciado diacronicamente. Por outro lado, como diz François Ost ${ }^{1}$ "o tempo é um dos maiores desafios da capacidade instituinte do direito".

E por um cacoete de ofício, já que sou historiador do direito por formação, e também porque as circunstâncias permitem, gostaria de ter como fio condutor desta fala o TEMPO. Afinal, todos somos captados, envolvidos por ele. Como diz Caetano, é o tempo esse "compositor de destinos e tambor de todos os ritmos". Como diz Drummond, é o tempo esse "agente de transformação".

Nada e nem ninguém é infenso à passagem do tempo. A transformação é inevitável,

1 OST, François. O tempo do direito. Trad. Elcio Fernandes. Bauru: EDUSC, 2005, p. 14. 
inexorável. É o que já dizia Heráclito de Éfeso, é o que dizia Hegel, é o que dizia Marx. A mudança é dialética, produz síntese, é "Aufhebung", é elevação e superação. A mudança é da ordem das coisas. O ser é também um "vir-a-ser".

Mas não há síntese sem tese, como também não há síntese sem antítese. E por isso é necessário dizer que qualquer ato, qualquer iniciativa, qualquer porvir não vem do nada, mas recebe o tempo que o precedeu, do qual ele é devedor. Sem ele, nada se constrói. Pensar de maneira contrária seria recair no idealismo: somos todos históricos, radicalmente históricos, e o mundo que recebemos provém do mundo que outros já habitaram.

E o tempo envolve-nos todos. A mim, aos estudantes, a todos os colegas aqui presentes. E envolve também o Setor de Ciências Jurídicas - onde se sói usar o termo "faculdade de direito" como referência aos tempos de resistência, tanto à ditadura militar quanto à reforma universitária que departamentalizou os cursos. Aqui o tempo é elemento importante. Aqui se cultiva a tradição - pois o curso de direito foi um dos primeiros que compôs a Universidade no ano de 1912, de modo que, quando a Universidade completar cem anos, no fim da gestão que agora se inicia, o curso de direito também completará seu centenário. E, não por acaso, os nomes que por aqui passaram, os mestres que aqui lecionaram e sobretudo as autoridades políticas e judiciais que aqui aprenderam são com frequiência lembrados.

E esse tempo cultuado pela tradição é importante. Num momento em que existem mais de trinta cursos de direito na cidade de Curitiba e na sua região metropolitana, ter uma história de quase cem anos é uma insígnia e é um diferencial. Como também é um orgulho, ao longo desse tempo, ter tido em nosso rol os maiores mestres do direito que nosso Estado conheceu.

Mas a tradição, em si mesma, não basta. Como historiador do direito que sou, por ofício sei que o mero culto ao passado, a mera elegia de efígies e repetidas homenagens encomiásticas a nomes de outrora podem degenerar numa museologia sem sentido, que, ao cultuar o passado, embalsama-no e isola-o do presente; um presente que exige intervenção, um presente que precisa, desesperadamente, olhar para si mesmo e para o futuro.

Pela sensibilidade de historiador que tenho, sei da importância do tempo passado. Sei que somos herdeiros, inevitáveis herdeiros de uma tradição. Como diz o filósofo alemão Walter Benjamin, "A felicidade capaz de suscitar nossa inveja está toda, inteira, no ar que já respiramos, nos homens com os quais poderíamos ter conversado, nas mulheres que poderíamos ter possuído". Sei, portanto, que devemos muito à tradição - e no caso da Faculdade de Direito isso é mais do que verdadeiro, pois aqui existiram e existem grandes mestres, exemplos para a ciência, e aqui também foi em várias oportunidades palco da resistência, especialmente no período da ditadura militar. Mas sei também repito - que não podemos ser prisioneiros de um passado que não dialogue com o futuro. Sei que ainda que sejamos herdeiros de uma grande genealogia, devemos lembrar que

2 BENJAMIN, Walter. Sobre o conceito de história "in”__ Obras escolhidas: magia e técnica, arte e política. Trad. Sergio Paulo Rouanet. São Paulo: Brasiliense, 1987, p. 222/223. 
numa sociedade pós-iluminista é descabido um culto à tradição que sirva à perpetuação de um sistema de castas, de diferenciação por origem, de diferenciação por ofícios. Quando falo do tempo da tradição, então, quero me referir a uma herança, a uma valiosíssima e preciosa herança que deve nos capacitar a firmar compromissos com o presente e com o futuro. Pois, como diz o mesmo Benjamin, "o passado traz consigo um índice misterioso, que o impele à redenção" 3 . Diz ainda que é "irrecuperável cada imagem do passado que se dirige ao presente sem que esse presente se sinta visado por ela" ", o que indica que só há sentido em vincular-se ao passado quando se tem os pés bem plantados no presente e os olhos bem fixados no futuro. Por isso, o mesmo Benjamin conclui, "existe um encontro secreto, marcado entre as gerações precedentes e a nossa"5. Pois esse encontro, senhoras e senhores, está acontecendo agora, neste salão nobre.

Sem renunciar à riqueza da tradição, da boa tradição democrática e acadêmica que sai por detrás destas colunas, é chegado o tempo de mudanças. Isso porque a sociedade muda, a epistemologia muda, o mundo muda. E em meio a estas mudanças o curso de direito da Universidade Federal do Paraná deve estar na vanguarda, deve estar acima do rés do chão da prática cotidiana, deve saber olhar longe.

Não quero com isso desfazer o compromisso que este curso de direito tem já há muito tempo com a formação de profissionais altamente qualificados, com preparo técnico inquestionável, com aptidão

\footnotetext{
3 Idem, p. 223.

4 Idem, p. 224.

5 Idem, p. 223.
}

para o desempenho da advocacia privada e pública, da magistratura, das funções do Ministério Público ou de qualquer outra profissão do direito. Temos a responsabilidade de formar nossos bacharéis para o mercado, para que sejam os melhores, e por isso é um compromisso irrenunciável dotar os estudantes de uma sólida formação técnica e dogmática. E isso tem acontecido, como se pode verificar com muita facilidade pelos índices de aprovação no teste da $\mathrm{OAB}$, na qual os estudantes de direito da UFPR têm sido aqueles que mais são aprovados. Tem acontecido pelo que se pode verificar pelas listas dos aprovados nos vários concursos públicos das carreiras jurídicas.

Mas o que acho - e repito, sem descurar desse front crucial - é que nossa vocação como curso de direito em uma Universidade Pública não pode se amesquinhar e se restringir a uma mera formação técnica. Queremos os melhores advogados, mas queremos também os advogados mais éticos e responsáveis. Queremos os melhores juízes, mas queremos também os magistrados mais sensíveis e justos. Queremos os melhores membros do Ministério Público, mas queremos também um parquet ao mesmo tempo comprometido e ponderado. Queremos os melhores delegados, mas queremos também uma polícia humana e incorruptível.

Nossa vocação de praticar o ensino jurídico em uma Universidade pública pede mais (e nosso tempo urge para que assim o façamos): queremos um ensino de qualidade, mas que não se alheie em nenhum momento da sociedade na qual o mundo do direito se insere e se nutre. E estar em uma universidade pública não significa somente que esta sociedade - esta carente sociedade em que 
vivemos! - financia este curso de direito, que paga os professores e isenta os estudantes de mensalidade. Significa também que devemos nos orientar por uma racionalidade pública, racionalidade pública que nos indica a necessidade de mesmo estando atentíssimos ao mercado, não nos comprometamos, nem nos vinculemos a ele, e muito menos sejamos seus servos. Significa que temos um compromisso com a pesquisa, temos um compromisso com a extensão e devemos articulá-las adequadamente com o ensino. Significa que temos um compromisso com a sociedade que nos financia e com a história que recebemos. Afirmemos com força, junto com o jurista italiano Paolo Grossi, que deve ser resgatada a humanidade e a socialidade do direito ${ }^{6}$.

Ensinar direito, neste novo tempo, por isso tudo, não pode ser mais a mera repetição e exegese das leis e códigos, a mera acumulação vazia de saberes - saberes que a galope estão sendo superados por outros. Hoje, também no direito cumpre-se a previsão de Marx e Engels feita em 1848, segundo a qual "tudo que é sólido desmancha no ar, tudo que é sagrado é profanado" . Hoje a pura acumulação e memorização de saberes será tão vã quanto o era para Irineu Funes, o memorioso, no célebre conto de Jorge Luis Borges, que registrava e recordava cada minúsculo detalhe e movimento do mundo que o envolvia, que era capaz de catalogar as

6 GROSSI, Paolo. Primeira lição sobre direito. Trad. Ricardo Marcelo Fonseca. Rio de Janeiro: Forense, 2006, p. 6 e segs.

7 MARX, Karl e ENGELS, Friedrich. Burgueses e proletários (excerto do Manifesto comunista) "in" MARX, Karl. História (organizador: Florestan Fernandes). 2.ed. São Paulo: Ática, 1984, p. 368. mínimas diferenças, e o ônus desse registro incomensurável de dados acabava sendo para ele uma pesada sina. Ao tanto registrar e recordar, Funes acabava se mostrando incapaz de pensar. Nas palavras de Borges, "Pensar é esquecer diferenças, é generalizar, abstrair. No abarrotado mundo de Funes não havia senão pormenores, quase imediatos". 8

Ensinar direito, no nosso tempo, significa ensinar a pensar.

Recorro ainda a Goethe, que numa carta a Schiller disse: "me é odioso tudo o que simplesmente me instrui, sem aumentar ou imediatamente vivificar minha atividade". 9 Na universidade pública trata-se de vivificar e aumentar nossa atuação.

Precisamos, por isso, de um novo projeto didático pedagógico, que acabe por desembocar necessariamente num currículo novo, que esteja apto a assimilar esse tempo de mudanças, um currículo que, dentro das limitações que temos justamente em vista de nossa racionalidade pública, seja também capaz de abrir-se para o novo que pulula na sociedade, de receber as novas e velozes demandas de nosso direito, que seja capaz de refletir. Isso tudo sem opor artificialmente as disciplinas teóricas formativas e as profissionais, mas implicando-as e criando condições para que os diferentes tipos de juristas (os da aplicação e os da teoria) possam conjugar-se dialeticamente. Ao dizer isso, tenho como horizonte não algo inatingível, mas algo concreto, aquilo que

8 BORGES, Jorge Luis. Ficções. Trad. Carlos Nejar. 7.ed. São Paulo: Globo, 1997, p. 116/117.

9 Apud NIETZSCHE, Friedrich. Segunda consideração intempestiva: da utilidade e desvantagem da história para a vida. Trad. Marco Antonio Casanova. Rio de Janeiro: Relume Dumará, 2003, p. 5. 
os historiadores do pensamento jurídico bem conhecem: é o tempo (da segunda metade do século XIX e primeira metade do século XX) da riquíssima dogmática alemã, que em muitos sentidos é mãe do direito contemporâneo, dogmática alemã na qual os civilistas (como Savigny) eram também historiadores e romanistas e os penalistas (como Welzel) eram também filósofos.

Aqui a dogmática jurídica, mesmo na sua especificidade técnica, e claro que respeitadas as competências de nossos mestres, deve dialogar ou ao menos estar aberta às várias áreas do saber, pois essa, creio, é uma exigência de nosso tempo.

O novo projeto didático pedagógico tem que encontrar um lugar central para a pesquisa. A verdadeira academia dotada de racionalidade pública é um lugar de produção qualificada de saberes, e essa produção de saberes, por outro lado, deve ter como local privilegiado de divulgação e discussão a sala de aula, de modo que a implicação e a indissociabilidade entre o ensino e a pesquisa devem ser fortemente reafirmadas. Tudo isso sem prejuízo de que se fomentem eventos, colóquios, seminários, congressos, redignificando esse espaço com um dos grandes pólos da discussão da ciência jurídica brasileira.

É necessário fomentar a pesquisa docente e discente, em conjunto com nossa pósgraduação, estando atento à necessidade de crescente internacionalização. É necessário levar muito a sério as formas de divulgação de nossas pesquisas, mantendo nossa revista com fortes critérios de exogenia e de impessoalidade, de qualidade e de grande circulação.

O novo projeto didático pedagógico também tem que repensar o lugar da extensão no curso de direito. Devemos fomentar a criação e ampliação de projetos de extensão, articulando-os adequadamente com as atividades de pesquisa e ensino, estudando a viabilidade de inserir este componente de modo efetivo na própria formação do graduando.

Temos que redignificar o Núcleo de Prática Jurídica - hoje um grande projeto de extensão da Universidade. Temos que, ali, estar atentos à adequada e sólida preparação técnica de nossos estudantes, para capacitálos à vida profissional, mas entendendo esse núcleo como algo inserido numa racionalidade pública que exige que nós assumamos responsabilidades. A partir dessa premissa temos que refletir sobre a inserção que faremos na sociedade e sobre o modo como o curso de direito fará sua inflexão cidadã com os mais carentes.

O novo projeto didático pedagógico deverá dar especial atenção à biblioteca, sua constante ampliação e suporte do ponto de vista logístico e de pessoal.

E nesse esforço o Setor de Ciências Jurídicas quer poder contar e estar de braços dados com a administração da Universidade, pois as carências que temos não são pequenas. Não é só a biblioteca que necessita de mais servidores e maior tempo de funcionamento; todo o curso noturno necessita de um impulso administrativo e de pessoal.

E tudo isso, enfim, deve ser feito com racionalidade pública. Isso significa que a gestão do Setor deve ter como premissa a responsabilidade, o debate e os interesses republicanos. Este curso será gerido com diálogo, com entendimento, com paz institucional. Os departamentos serão respeitados, o colegiado de curso será 
respeitado, as solidariedades institucionais serão reativadas. Com isso, creio que será natural que as solidariedades acadêmicas sejam também reforçadas. As eventuais e naturais divergências serão colocadas sobre a mesa e serão publicamente debatidas e resolvidas, como convém a uma universidade democrática. Não existirá nesta gestão a política do segredo ou do rumor.

Essa gestão encarará, ainda, dois grandes desafios: o primeiro será gerir a sua sensível ampliação, já a partir do próximo ano, em vista da adesão ao REUNI e ao conseqüente aumento do número de vagas de estudantes. Desafio que envolve nova distribuição de espaço, novas vagas docentes, certamente novos servidores. Crescer no âmbito do ensino público de qualidade é importante, mas é igualmente importante crescer com equilíbrio, crescer sem comprometer o nível de excelência que marca esta escola. Crescer zelando sempre pela higidez dos concursos públicos, para que aqui entrem os melhores, já que de fato os melhores professores e cientistas têm a Praça Santos Andrade como meta. Crescer zelando pela melhor gestão dos recursos. Crescer como instituição. Crescer com diálogo.

Creio que devemos conectar nossa discussão sobre a reforma curricular com a discussão sobre a ampliação do curso decorrente da adesão ao REUNI, de modo a otimizar energias e esforços, de melhor aproveitar vagas docentes e espaços, sempre dentro de uma racionalidade pública, sempre dentro dos critérios de excelência que são a nossa insígnia.

O segundo desafio é a preparação para o centenário da Universidade e do curso de direito. Vamos organizar e retirar do abandono a riquíssima documentação histórica que aqui mantemos. Vamos conservar nosso acervo documental e também nossa biblioteca histórica, certamente uma das mais (se não for a mais) preciosa do Sul do Brasil. E vamos preparar um projeto para, ao final da gestão, apresentar a história da faculdade no seu centenário. Na linha já iniciada em publicação editada na gestão em que foi diretor o prof. Alcides Munhoz da Cunha, vamos buscar o aprofundamento do conhecimento do nosso passado.

Em 1927, quando do centenário das duas primeiras faculdades de direito do Brasil, Clóvis Beviláqua, no Recife, e Spencer Vampré, em São Paulo, escreveram as "Memórias" destas faculdades em seus centenários, publicações que são hoje essenciais para todos os especialistas que voltam os olhos ao passado na busca de conhecimento. Faremos o mesmo aqui, talvez sem o caráter encomiástico e meramente celebrativo, pois não se pode renunciar, quando se olha para o passado, da crítica e da compreensão, o que certamente contribuirá para que todos possamos conhecer melhor a nós mesmos.

E com isso reafirmo todos os meus compromissos assumidos na campanha, e que fizeram a maioria absoluta do corpo docente desta Casa a confiar neste projeto de gestão.

Todos esses compromissos, todavia, que são feitos olhando para dentro das paredes do prédio histórico da Santos Andrade, compromissos de gestão para a construção de um novo tempo no curso de direito da UFPR, não excluem também o necessário e desejado diálogo do Setor de Ciências Jurídicas com os demais setores e órgãos da Universidade. Diálogo que se fará com 
respeito, mas que se fará também exigindo o respeito, respeito que merece um dos cursos que inaugurou esta Universidade, um dos cursos que obtém os melhores resultados em todas as avaliações institucionais, num setor que tem um dos programas de pós-graduação melhor avaliados em sua área no Brasil (e que foi o primeiro programa com nota 6 concedido pela CAPES em toda a Universidade). Um curso que, por tudo isso, faz seu papel e contribui para engrandecer o nome da Universidade Federal do Paraná.

O curso de direito, retomando este diálogo, reivindicará seu papel central na discussão da democracia universitária e no debate sobre os rumos institucionais que deverão ser seguidos - papel central que já foi ocupado nos momentos de arbítrio e no momento da redemocratização (apesar, é claro, dos momentos de desvio e de alienação política que aqui também ocorreram). $\mathrm{O}$ direito quer e o direito merece voltar a ser interlocutor com os demais saberes.

É importante lembrar que houve um tempo histórico, justamente quando do nascimento das universidades na era medieval, em que o jurista era antes de tudo um intelectual, pois era o principal leitor/intérprete do seu tempo; era aquele a quem cabia fazer a necessária "mediação entre cosmologia e o modo de viver em sociedade".

É importante lembrar que houve um tempo histórico em que o jurista, a partir de sua profunda compreensão da ligação necessária entre direito e sociedade, era o intérprete da ordenação social, era o mediador da natural observância da sociedade às regras de um bem viver, era o porta voz e principal seguidor do primado da justiça e da "aequitas".
Houve um tempo em que o jurista era o protagonista da cena política no Brasil - e embora aquilo que ficou sendo conhecido como "república dos bacharéis" tenha tido um perfil liberal, conservador e elitista, era um período em que na discussão política, para o bem ou para o mal, os direitos é que eram colocados em primeiro lugar em cena, e não as estatísticas econômicas, e em que a política é atravessada pelos argumentos de uma tecnocracia com uma racionalidade voltada para o atingimento de resultados financeiros e muito menos pelos valores jurídicos que estão plasmados na nossa Constituição da República, como, por exemplo, a dignidade da pessoa humana e a efetiva redução das desigualdades.

Digo isso sem nenhuma pretensão de arrogância e de superioridade. Esta gestão reinvindica o lugar do direito, mas respeita profundamente todos os demais saberes e áreas. Pretende-se somente retomar seu lugar no debate sem ser confundido com um burocrata especializado em sutilezas, que preza pelos benefícios da retórica e que está alheado da compreensão das efetivas contradições e conflitos da sociedade. Aqui, no curso de direito da UFPR, o jurista quer dialogar, debater, participar e contribuir.

Nesse sentido de contribuição, o Setor de Ciências Jurídicas vislumbra a Universidade como o baluarte da produção e da reprodução do saber, como a oficina do pensamento e, ao menos idealmente, como a oficina da crítica, entendida aqui a crítica como a superação teórica dos horizontes existentes, do imediato, da vida na rés do chão, para buscar olhar mais penetrante, mais incisivo e que veja mais longe, que enxergue na vida do homem a perspectiva e a possibilidade de superação 
daquilo que não pode ser tolerado na vida, daquelas ignomínias, vergonhas e injustiças que cada época histórica traz consigo.

Vislumbra-se a universidade como um legado inestimável da nossa história. Mas como a história é complexa e contraditória, e é permeável às lutas que permanentemente se travam em seu seio, não podemos deixar de estar atentos aos perigos constantes que nos espreitam.

Discordamos de uma política que coloca o equilíbrio fiscal do Estado acima de qualquer outro valor.

Discordamos da tenaz inanição de recursos públicos a que está sendo submetida a Universidade Pública, que é muitas vezes impelida a seguir uma racionalidade privatizante (apesar das bravas resistências), correndo o risco de, no plano histórico-social, igualar-se, nesse plano da racionalidade, ao cada vez maior contingente de instituições de ensino superior privado. Quero ressaltar que o ensino privado é fundamental e tem um papel central na qualificação educacional brasileira. Somente acentuo que o ensino público tem outra racionalidade, uma racionalidade pública que é um valor pelo qual devemos lutar, como estamos lutando, dioturnamente.

Afinal, só uma Universidade Pública tem a vocação natural de ter uma gestão em que todos possam participar, dentro de uma discussão que seja norteada pelos valores acadêmicos, e não pessoais, econômicos ou de poder. E o Setor de Ciências Jurídicas quer se colocar como um agente e um fiscal da democratização crescente da Universidade, tanto no plano formal (buscando discutir com maturidade e responsabilidade a crescente participação de todas as categorias nos processos de decisão institucional) quanto no plano material. O Setor de Ciências Jurídicas lutará para que a Universidade seja radicalmente ligada a valores acadêmicos, impessoais, desvinculada de quaisquer cesarismos e projetos individuais que façam sombra à vocação que é - e deve sempre ser fundamentalmente acadêmica.

Afinal, é a Universidade Pública que tem a vocação natural de desenvolver a pesquisa que seja atravessada por uma finalidade também pública, que seja de todos e que possa ser repartida por toda a sociedade, e que seja tendencialmente infensa às sempre interessadas necessidades do mercado (inclusive do mercado do ensino). Afinal, só uma Universidade Pública tem a vocação natural de aliar essa pesquisa com um ensino que também seja guiado por valores republicanos.

É na Universidade pública que, por excelência, se deve dedicar, tomando os dizeres de Zygmunt Bauman ${ }^{10}$, ao culto de um saber clínico, e não a um saber cínico. Um saber clínico que seja analítico, que seja infenso aos modismos e oportunismos, que seja inflexível na seriedade acadêmica, mas que seja ao mesmo tempo imbricado com os dilemas do nosso tempo e que seja sensível aos problemas do mundo sobre o qual ele se debruça. E que seja o oposto de um saber cínico, o oposto de um saber cheio de moralismos, de interdições, de um saber que levante trincheiras contra o necessário e saudável pluralismo que deve caracterizar uma universidade, o oposto de um saber que

${ }^{10}$ BAUMAN, Zygmunt. Em busca da política. Trad. Marcus Penchel. Rio de Janeiro: Jorge Zahar, 2000. 
suba barricadas contra a articulação da universidade com a sociedade.

E aqui se aponta um novo vetor - que na verdade é também um grande desafio que o Setor de Ciências Jurídicas desde já se coloca e coloca para a comunidade universitária: a necessidade de reflexão da comunidade acadêmica - mercê de nossa irrenunciável racionalidade pública - de relacionar-se de maneira responsável e comprometida com a sociedade. Numa sociedade como a nossa, a ciência e a tecnologia precisam desenvolver-se com premência, mas ao mesmo tempo (sem que aqui vejamos vocações conflitantes) a Universidade não pode se alhear e se alienar das nossas vicissitudes, de nossas carências, de nossas emergências. Devem ser pensadas as múltiplas formas pelas quais sociedade e universidade podem se relacionar com higidez, proveito recíproco e responsabilidade. A universidade deverá enfrentar esse desafio, para o qual o setor de ciências jurídicas desde logo já se coloca, com disposição, para o aprofundamento teórico e para a inserção prática.

Senhoras e senhores, recebemos agora uma herança, recebemos um tempo. Espero junto com meus colegas estar à altura das responsabilidades que nos esperam. E se for necessário irromper a linearidade aparente do devir, teremos a coragem de assim proceder. Essa é a beleza da temporalidade. Como, mais uma vez, diz Caetano, "Por seres tão inventivo, e pareceres contínuo, tempo, tempo, tempo, és um dos deuses mais lindos".

O tempo está em nossas mãos. Chamo toda a comunidade acadêmica do direito para, com diálogo, com responsabilidade e com compromisso, pavimentarmos juntos nosso caminho para o futuro. Inventemos um novo tempo.

E eu encerro citando Helena Kolody, que num "Convite à viagem", traduziu com maestria um momento de alegria, de otimismo e de grandes desafios, que antecedem uma jornada e que, se me permitem a confissão, revelam agora o meu estado de espírito.

\section{Diz ela:}

Já se apresta o navio.

A marujada canta,

Marulha e arfa o mar,

O céu palpita

Deixa esse continente inóspito que habitas Iça teu sonho - vela branca - em altos mastros

E singra, solitário, rumo aos astros.

Nem tempo, nem espaço a perturbar a viagem...

Navegas ao sabor do pensamento

Por águas infinitas. ${ }^{I I}$

Muito obrigado.

11 KOLODY, Helena. Antologia poética. Curitiba: imã publicidade, 1994, p. 97. 